\title{
Crystal structure dependent photocatalytic degradation of manganese and titanium oxides composites
}

\author{
Moushumi Dutta Purkayastha ${ }^{1} \cdot$ Shanku Denrah ${ }^{2} \cdot$ Nisha Singh $^{3} \cdot$ Mitali Sarkar $^{2} \cdot$ Gopala Krishna Darbha $^{3,4}$. \\ Tapas Pal Majumder ${ }^{1}$
}

Received: 31 December 2019 / Accepted: 19 May 2020 / Published online: 26 May 2020

(c) Springer Nature Switzerland AG 2020

\begin{abstract}
Crystalline hexagonal disk-shaped anatase $\mathrm{TiO}_{2}$ within manganese oxide $\left(\mathrm{Mn}_{2} \mathrm{O}_{3}\right)$ nanorods has been fabricated to form manganese oxide-titanium dioxide (MnT) composites following sonochemical approach. The unique morphology of the synthesized MnT provides higher surface area to enhance the adsorption efficiency and promotes electron-hole separation. This appears particularly promising for efficient photocatalysis. The photocatalytic decolorization efficiency (PD) of sonosynthesized MnT (S-MnT) was tested via decomposition of an organic pollutant, malachite green oxalate under ultraviolet irradiation and compared to that of sol-gel synthesized $\mathrm{MnT}(\mathrm{H}-\mathrm{MnT})$. The profound impact of hydrogen peroxide $\left(\mathrm{H}_{2} \mathrm{O}_{2}\right)$ addition on the photoactivity was tested. $\mathrm{S}-\mathrm{MnT}$ with addition of sonicated $\mathrm{H}_{2} \mathrm{O}_{2}$ showed the best photoactivity (PD 99.61\% in $50 \mathrm{~min}$ ) in comparison to sol-gel synthesized H-MnT (PD 92.14\% in 60 min). The mechanism of degradation was found to depend on the formation of superoxide radicals $\left(\mathrm{O}_{2}^{-}\right)$, hydroxyl radicals $(\mathrm{OH})$ and the defect concentration. The role of ultrasound in the overall degradation process was also discussed. Photoluminescence studies demonstrate that $\mathrm{Mn}^{2+}$ ions are in an octahedral and tetrahedral coordination in both the composites which is favourable for light emission.
\end{abstract}

Keywords Sonosynthesis · Morphology $\cdot$ Hydrogen peroxide $\cdot$ Photocatalysis $\cdot$ Luminescence

\section{Introduction}

Non-silica mesoporous materials have inspired remarkable research interest as they are expected to serve as novel photocatalysts, semiconductors, electrode materials etc. [1]. Among these novel materials, titanium dioxide $\left(\mathrm{TiO}_{2}\right)$ is one among the most investigated functional materials in recent years $[2,3]$. Nevertheless, the main problem with $\mathrm{TiO}_{2}$ photocatalysis lies in the separation of photoinduced electron-hole pairs. To overcome this issue, different routes have been proposed which include combining the photocatalyst with another transition metal semiconductor [4], incorporation of non-metal ions [5] and by adding some sacrificial agent into the reaction system [6, 7]. Available methods for the formation of the binary composites include the sol-gel route [8], co-precipitation method [9], self-assembly [10] and a chelating agent-assisted precipitation method [11], although each suffers from conventional drawbacks.

Electronic supplementary material The online version of this article (https://doi.org/10.1007/s42452-020-2933-7) contains supplementary material, which is available to authorized users.

$\checkmark$ Tapas Pal Majumder, tpmajumder1966@gmail.com | 'Department of Physics, University of Kalyani, Kalyani, West Bengal 741235, India. ${ }^{2}$ Department of Chemistry, University of Kalyani, Kalyani, West Bengal 741235, India. ${ }^{3}$ Department of Earth Sciences Centre for Climate and Environmental Sciences, Indian Institute of Science, Education and Research Kolkata, Mohanpur, West Bengal 741246, India. ${ }^{4}$ Centre for Climate and Environmental Sciences, Indian Institute of Science, Education and Research Kolkata, Mohanpur, West Bengal 741246, India. 
The widely used sol-gel route is characterized by poor dispersion and requirement of complexing agents to control the homogeneous crystallization of dopant inorganic precursors [12] while interfacial self-assembly methods [10] have various technical issues that remain unaddressed. In recent times, sonochemical synthesis of nanocomposites has gained momentum because of its cost-effectiveness and simplicity $[13,14]$. Pressure and temperature changes during sonosynthesis result in the production of free radicals that in turn can reduce metal ions to metal or metal oxide nanoparticles $[15,16]$.

Aquatic ecosystems are continuously being contaminated by dye pollutants and have reached at an alarming point. These organic pollutants can be degraded to benign by-products by advanced oxidation processes which exploit the high reactivity of the hydroxyl radicals $(\mathrm{OH})$ as their driving force. The rate of generation of ' $\mathrm{OH}$ radical is, however, dependent on the type of crystal polymorphs. It is believed that a correlation exists between the rates of $\mathrm{OH}$ radical generation and the photocatalytic reactivity [17]. The photoinduced electrons and holes in the photocatalytic process react with $\mathrm{H}_{2} \mathrm{O}$ and $\mathrm{O}_{2}$ to give rise to several reactive oxygen species. Among the various reactive oxygen species, $\mathrm{H}_{2} \mathrm{O}_{2}$ is the most stable one. It is environment friendly and has high oxidative power $[18,19]$. However, its behaviour on semiconducting particles is very complex. During photocatalytic reactions, it is not only formed but also gets decomposed. Kim et al. [20] have suggested that the difference in the reactivity of anatase and rutile $\mathrm{TiO}_{2}$ can be ascribed to their adsorption capability of the $\mathrm{OH}$ radicals. Many researchers have investigated the formation rate of $\mathrm{OH}$ radicals for various kinds of $\mathrm{TiO}_{2}$ powders along with the effect of small amounts of $\mathrm{H}_{2} \mathrm{O}_{2}$ addition [21-24] but none have discussed the method of addition of these agents.

In the present communication, two different $\mathrm{Mn}_{2} \mathrm{O}_{3}-\mathrm{TiO}_{2}$ (MnT) nanocomposites have been synthesized following conventional sol-gel route and an ultrasound assisted cost-effective technique. Two different morphologies, hexagonal nanodisks and nanorods were distinctly observed in the sonosynthesized composite in comparison to sol-gel synthesized composite which showed only hexagonal nanodisks. The focus of this work is to investigate the synergistic photocatalytic degradation of malachite green (MG) in aqueous conditions with addition of $\mathrm{H}_{2} \mathrm{O}_{2}$ under ultraviolet (UV) irradiation by the synthesized nanocomposites.

\section{Experimental section}

\subsection{Materials required}

Titanium (IV) n-butoxide, manganese acetate tetrahydrate was procured from Sigma Aldrich and sodium hydroxide $(\mathrm{NaOH})$, ethanol, stearic acid, hydrogen peroxide ( $30 \%$ purified) from Merck and malachite green oxalate from PubChem.

\subsection{Method of preparation}

Ultrasonic irradiation $(40 \mathrm{kHz}, 480 \mathrm{~W})$ served the base for synthesis of S-MnT nanocomposite. Titanium tetra butoxide $\left(1.0 \times 10^{-2} \mathrm{M}\right)$ was added drop wise into $100 \mathrm{~mL} \mathrm{NaOH}\left(1.0 \times 10^{-3} \mathrm{M}\right)$ in an ice bath. The mixture was then subjected to ultrasonic irradiation using a bath sonicator for a period of $3 \mathrm{~h}$ at a temperature of $80^{\circ} \mathrm{C}$. Fresh flow of water was introduced in the bath whenever required to maintain temperature. To this solution, $10 \mathrm{~mL}$ ethanolic solution of manganese acetate tetrahydrate $\left(1.0 \times 10^{-1} \mathrm{M}\right)$ mixed with $0.5 \mathrm{M}$ of melted $\left(80^{\circ} \mathrm{C}\right)$ stearic acid was added and the mixture was subjected to ultrasonic irradiation for $5 \mathrm{~h}$. The final product (S-MnT) was washed with ethanol, filtered and dried at $120^{\circ} \mathrm{C}$ for $24 \mathrm{~h}$.

To properly understand the crucial influence of ultrasound governing the nanocomposite synthesis procedure, another MnT was prepared following the sol-gel route. Typically, titanium tetra butoxide $\left(1.0 \times 10^{-2} \mathrm{M}\right)$ was added drop wise to $100 \mathrm{~mL}$ of $\left(1.0 \times 10^{-3} \mathrm{M}\right) \mathrm{NaOH}$ solution and stirred vigorously (700 rev/s) for a period of $4 \mathrm{~h}$. Subsequently, $10 \mathrm{~mL}$ of ethanolic solution of manganese acetate tetrahydrate $\left(1.0 \times 10^{-1} \mathrm{M}\right)$ mixed with $0.5 \mathrm{M}$ of melted $\left(80^{\circ} \mathrm{C}\right)$ stearic acid was added. The contents were put in an autoclave, and heated at $130^{\circ} \mathrm{C}$ for $24 \mathrm{~h}$. The obtained product (H-MnT) was filtered, washed thrice with de-ionized water and dried at $200^{\circ} \mathrm{C}$ for $5 \mathrm{~h}$.

\subsection{Characterization techniques}

An X'Pert PRO PANalytical X-ray diffractometer was used to obtain the diffraction patterns of the synthesized materials. Elemental composition and morphology were ascertained with a Field emission Scanning Electron Micrograph (Carl Zeiss SUPRA 55VP Field emission SEM) coupled with an Energy dispersive spectrometer (EDS). Functional groups present in the materials were confirmed with an Infrared (IR) spectrometer (Perkin Elmer Spectrum one L120-000A). The emission and absorption spectra were recorded with a PTI QM 40 spectrometer and UV 3600 spectrometer respectively. A surface area analyser (Micromeritics Gemini VII-2390t) was used to measure the surface area. The samples were degassed at $100^{\circ} \mathrm{C}$ and the total pore size distribution (PSD) was measured from the nitrogen desorption isotherm using the cylindrical pore model. 


\subsection{Degradation experiments}

A UV-vis-NIR spectrophotometer was utilized to monitor the photocatalytic behaviour of MnT nanocomposites. The photocatalytic tests were carried out with an aqueous solution of malachite green oxalate (molecular formula $\mathrm{C}_{52} \mathrm{H}_{54} \mathrm{~N}_{4} \mathrm{O}_{12}$, PubChem, CAS 2437-29-8) as the test contaminant in a reaction chamber enclosed within a wooden chamber fitted with UV lamps (Philips TUV $30 \mathrm{~W}$ T8). Arrangement of the reactor was such that UV light was directly incident on the samples. The photon flux has been calculated by a method discussed in M.D. Purkayastha et al. [2]. Prior to photocatalytic experiments, the aqueous dye solution was subjected to UV irradiation for $1 \mathrm{~h}$ to check whether photolysis occurs. Also, the adsorption behaviour of the photocatalysts for MG dye was tested without UV light irradiation. To achieve this, the photocatalysts were dispersed in the aqueous dye solution and stirred in dark for $1 \mathrm{~h}$. The photocatalytic activities of both the samples were evaluated by measuring the decomposition of MG under UV light with time. Typically, $50 \mathrm{~mL}$ aqueous solution of $\mathrm{MG}$ dye $(0.001 \mathrm{M})$ with $50 \mathrm{mg}$ of the photocatalyst was stirred in the reactor. Prior to stirring, the system was dispersed by ultrasonic waves. After subjecting to UV irradiation, $5 \mathrm{~mL}$ aliquots of the reaction solutions were removed from the reactor every $10 \mathrm{~min}$ for analysis. These aliquots were centrifuged at $1000 \mathrm{rpm}$ to exclude suspended particles, and the concentration of MG in the supernatant solutions was assessed by UV-Vis spectrometry at $618 \mathrm{~nm}, 315 \mathrm{~nm}$ and $418 \mathrm{~nm}$ absorption wavelengths for MG.

To analyse the influence of ultrasound on the behaviour of oxidizing species, photocatalytic degradation kinetic tests were repeated with optimal amounts of hydrogen peroxide $(2 \mathrm{~mL}$ ) added to S-MnT catalyst once directly and once after ultrasonication.

\section{Results and discussion}

\subsection{S-MnT synthesis}

Sonochemical methods of synthesis have been recently considered as a simple and efficient with the non-requirement of surfactants and complexing agents [25]. Addition of $\mathrm{NaOH}$ causes hydrolysis of titanium tetrabutoxide [Eq. (1)]. The hydrolytic species undergoes condensation and aggregation forming $\mathrm{TiO}_{2}$ under the effect of sonication at an elevated temperature of $80^{\circ} \mathrm{C}[13,26,27]$.

$\mathrm{Ti}\left(\mathrm{OC}_{4} \mathrm{H}_{9}\right)_{4}+4 \mathrm{H}_{2} \mathrm{O} \rightarrow \mathrm{Ti}(\mathrm{OH})_{4}+4 \mathrm{C}_{4} \mathrm{H}_{9} \mathrm{OH}$
$\mathrm{Ti}(\mathrm{OH})_{4} \rightarrow \mathrm{TiO}_{2}+2 \mathrm{H}_{2} \mathrm{O}$

Regarding the formation of $\mathrm{Mn}_{2} \mathrm{O}_{3}$, the precursor manganese acetate tetrahydrate is first dissolved in ethanol where it undergoes hydrolysis [9]. The use of stearic acid can modify the particle surface by introducing characteristic groups onto the surface of $\mathrm{Mn}_{2} \mathrm{O}_{3}$ to alter its physicochemical properties [28]. Also, the long carbon chains in stearic acid endow it with strong ability to disperse metal precursors [29]. The FTIR spectrum confirms the modification by showing a band corresponding to stearate. Similar predictions have been made by Kolodziejczak-Radzimska et al. [30]. Probably, changes in pressure and temperature due to ultrasonic irradiation caused $\mathrm{Mn}^{2+}$ ions to get oxidized to $\mathrm{Mn}_{2} \mathrm{O}_{3}$ that impeded the $\mathrm{TiO}_{2}$ particles to join forming rod like structures [31]. Similar observations have been made by Hu et al. [25] who synthesized connected rods of $\mathrm{ZnO}$ using a sonochemical process with an aqueous solution of $\mathrm{Zn}\left(\mathrm{NO}_{3}\right)_{2} \cdot 6 \mathrm{H}_{2} \mathrm{O}$ at a temperature of $80^{\circ} \mathrm{C}$ under ambient conditions.

\subsection{Structural characterization}

The diffraction pattern (Fig. 1a) of the pure $\mathrm{TiO}_{2}$ shows the presence of anatase peaks corresponding to the $\left(\begin{array}{ll}10 & 1\end{array}\right)$, (0 0 4), (2 0 0), (1 0 5), (211), (204), (116), (220) and (215) diffraction planes supported by JCPDS card no.78-2486. Figure $1 b, c$ depicts the XRD patterns acquired from the two representative samples $\mathrm{H}-\mathrm{MnT}$ and S-MnT. The diffraction peaks can be indexed to the mixtures of $\mathrm{TiO}_{2}$ anatase and bixbyite structure of $\mathrm{Mn}_{2} \mathrm{O}_{3}$ coinciding with JCPDS 24-0508. The S-MnT and H-MnT nano powders exhibited brown hue.

Sonication effect on size of the crystallites, and the phase was studied from the XRD pattern [32]. Both the



Fig. 1 XRD patterns of a TiO 2 , b H-MnT and c S-MnT 
composites favoured anatase phase of $\mathrm{TiO}_{2}$ in it. As shown in Fig. 1, the intensity of the (101) peak of $\mathrm{TiO}_{2}$ in the composites decreased remarkably in comparison to pure $\mathrm{TiO}_{2}$ anatase. However, the peaks of $\mathrm{H}-\mathrm{MnT}$ appeared slightly sharper in comparison to S-MnT showing signs of improved crystalline structure. Probably, the step-wise hydrolysis of tetrabutyl titanate affected the process of crystallization in S-MnT. It could be concluded from this that ultrasound had some impact on the crystallinity. On calculating the crystallite size by Scherer formula [33] corresponding to the most intense (101) peak of $\mathrm{TiO}_{2}$ in the composites, it was observed that sizes $(31.94 \mathrm{~nm}$ for $\mathrm{H}-\mathrm{MnT}$ and $24.18 \mathrm{~nm}$ for S-MnT) are comparable. Overall, sonosynthesis has little or no influence on crystallite size and phase of the synthesized samples.

The energy dispersive X-ray (EDS) spectra of both H-MnT (Fig. 2a) and S-MnT (Fig. 2b) confirm the presence of manganese (5.6-6.6 keV), titanium (4.5-5 keV) and oxygen (0-1 keV) [34]. It can be observed that the atomic weight percentage of manganese in S-MnT is much higher which suggests better dispersion of manganese in the formation of S-MnT composite.

The typical FESEM images of the as-synthesized samples presented in Fig. 2 shows that the morphology changes drastically with change in synthesis techniques. The sample S-MnT prepared with ultrasound generated
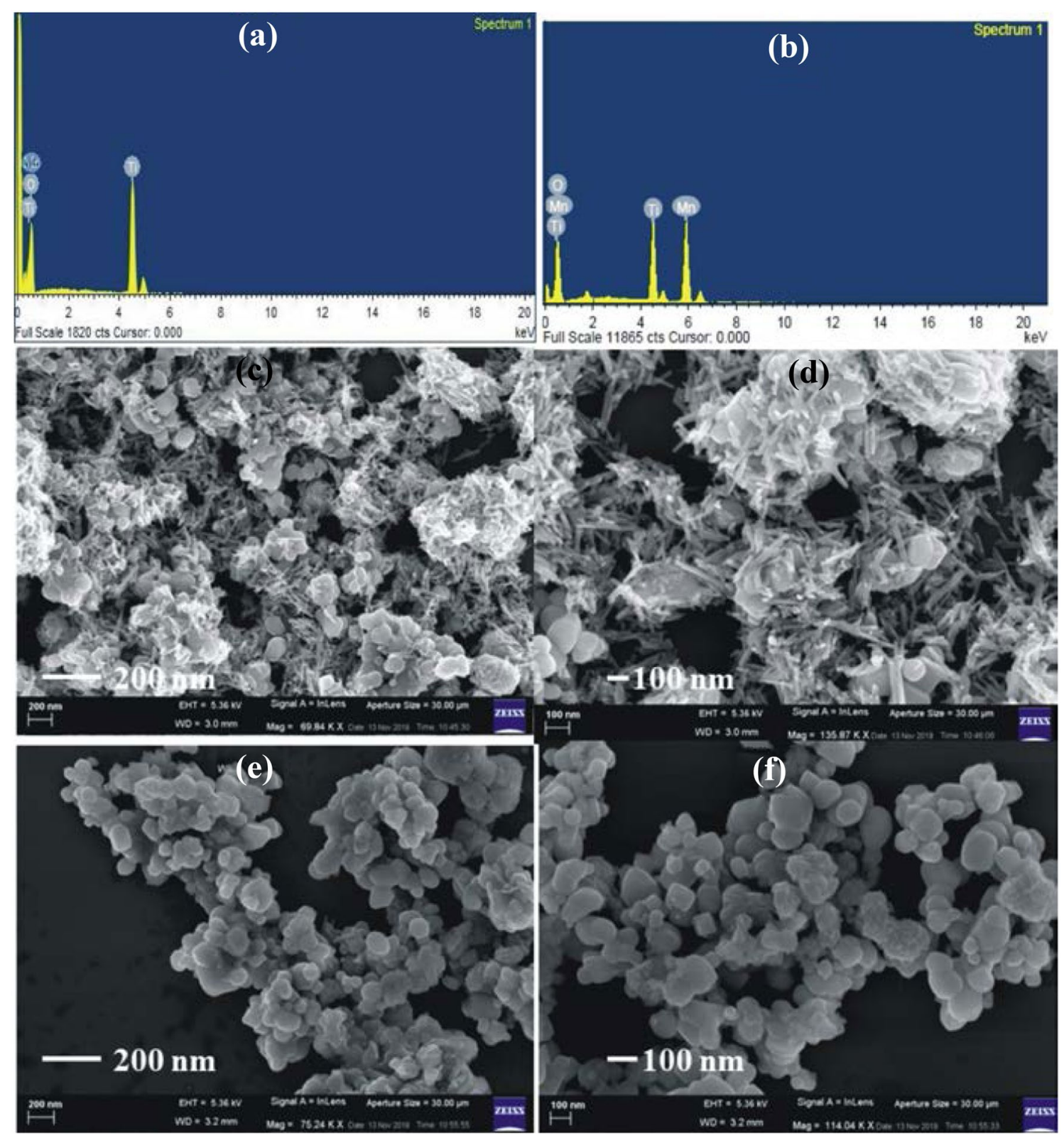

Fig. 2 a EDS image of H-MnT; $\mathbf{b}$ EDS image of S-MnT; $\mathbf{c}$ and FESEM images of S-MnT and $\mathbf{e}$ and $\mathbf{f}$ FESEM images of H-MnT 
nanorods along with nanodisks (Fig. 2c, d), while only hexagonal nanodisks could be observed for $\mathrm{H}-\mathrm{MnT}$ (Fig. 2e, f). It should be noted that these composite structures were synthesized maintaining all experimental conditions fixed except the use of ultrasound. Therefore, the evolution of diverse morphology is believed to be the result of ultrasound. The existence of diverse morphology in S-MnT could be because manganese impeded the hexagonal nanodisks to grow along preferred crystallographic direction forming nanorods under the influence of ultrasound. Thus, sonosynthesis can significantly influence the surface morphology of the nanoparticles which may have a profound effect on photocatalytic activity as well $[35,36]$.

The samples were dispersed in doubly distilled water in an ultrasonic bath and the absorbance spectrum was recorded (Fig. 3i). H-MnT showed absorption peaks at $238 \mathrm{~nm}$ and $377 \mathrm{~nm}$ corresponding to the UV region. These are characteristics peaks of $\mathrm{TiO}_{2}$ and found to coincide well with literature [37, 38]. Similar peaks were observed in the case of S-MnT. But the peak at $377 \mathrm{~nm}$ appeared red shifted by $5 \mathrm{~nm}$. The Tauc Eq. (3) was utilized to calculate the optical band gap $\left(\mathrm{E}_{\mathbf{g}}\right)$.

$\alpha h v=C\left(h v-E_{g}\right)^{n}$

where $a$ is the absorption coefficient and $\mathrm{n}$ signals the character of transition which assumes a value $1 / 2$ for direct, allowed transition. The band gap of $\mathrm{H}-\mathrm{MnT}$ was found to $2.44 \mathrm{eV}$ (Fig. 3ii). The synergistic effect of ultrasound brings down the band gap energy to $2.14 \mathrm{eV}$ for S-MnT (Fig. 3iii). Probably, ultrasound caused chemical bonding between $\mathrm{Mn}_{2} \mathrm{O}_{3}$ and $\mathrm{TiO}_{2}$ particles in the composite that led to band gap narrowing. The band gap energy values are lower than those reported by other researchers [39] which could be due to structural distortion resulting from oxygen deficiencies in the samples. Also, the S-MnT peaks showed higher intensity confirming the structural modification. Thus, sonochemistry is capable of tuning the band gaps and altering the light absorption properties of the samples as well.

IR spectra of S-MnT and H-MnT are illustrated in Fig. 4i. The peaks at $3400 \mathrm{~cm}^{-1}$ and $1627 \mathrm{~cm}^{-1}$ in both the samples can be assigned to the stretching vibrations of adsorbed water molecules and $\mathrm{OH}^{-}$in the lattice. $\mathrm{H}-\mathrm{MnT}$ and $\mathrm{S}-\mathrm{MnT}$ both show the characteristic peak of stearic acid at $1046 \mathrm{~cm}^{-1}$ used in their preparation which confirms that stearic acid is well incorporated in the structures [40]. The formation of bonds between metal and oxygen are confirmed from the peaks at $514 \mathrm{~cm}^{-1}$ and $730 \mathrm{~cm}^{-1}[29,40]$.

Manganese, being a transition metal ion, has a wide emission wavelength range and its location in the $\mathrm{TiO}_{2}$ lattice actually decides its luminescence properties [41]. The photoluminescence $(\mathrm{PL})$ properties of the samples under the UV excitation wavelength of $300 \mathrm{~nm}$ are presented in Fig. 4ii. Considering the Tanabe-Sugano diagrams [42] to demonstrate the PL mechanism, it can be assumed that due to UV excitation, electron transition occurs and the system is excited from the ${ }^{4} \mathrm{~A}_{2}$ ground state to the excited states of ${ }^{2} \mathrm{~T}_{1}$ and ${ }^{4} \mathrm{~T}_{2}$. These excited states are however not stable, and it is presumable that the system will relax and ultimately come down to the ground state ${ }^{4} A_{2}$ through a radiative transition. Previous studies have reported that a material can emit light corresponding to different wavelengths based on their arrangement within the lattice $[43,44]$. H-MnT showed emissions at $469 \mathrm{~nm}$ and $551 \mathrm{~nm}$ while for S-MnT (Fig. 4ii) these peaks appeared slightly red shifted. This red shift can be attributed to the evolution of defects [45]. The peak at $551 \mathrm{~nm}$ corresponds to yellow-orange (and also red) emission and is associated with deeper defects while that at $469 \mathrm{~nm}$ corresponds to blue-green emission which can be associated with surface defects [46, 47]. Manganese is known to have variable oxidation states. Report [48] claims that the emission band of $\mathrm{Mn}^{4+}$ ion stretches from 600 to $710 \mathrm{~nm}$ and is due to the ${ }^{2} \mathrm{E} \rightarrow{ }^{4} \mathrm{~A}_{2}$ transition. In the present case, a peak at $692 \mathrm{~nm}$ confirms the presence of $\mathrm{Mn}^{4+}$ ions in both



Fig. 3 (i) Absorption spectra of (a) H-MnT and (b) S-MnT; (ii) \& (iii) Band gap determination using Tauc plot of (a) H-MnT and (b) S-MnT 

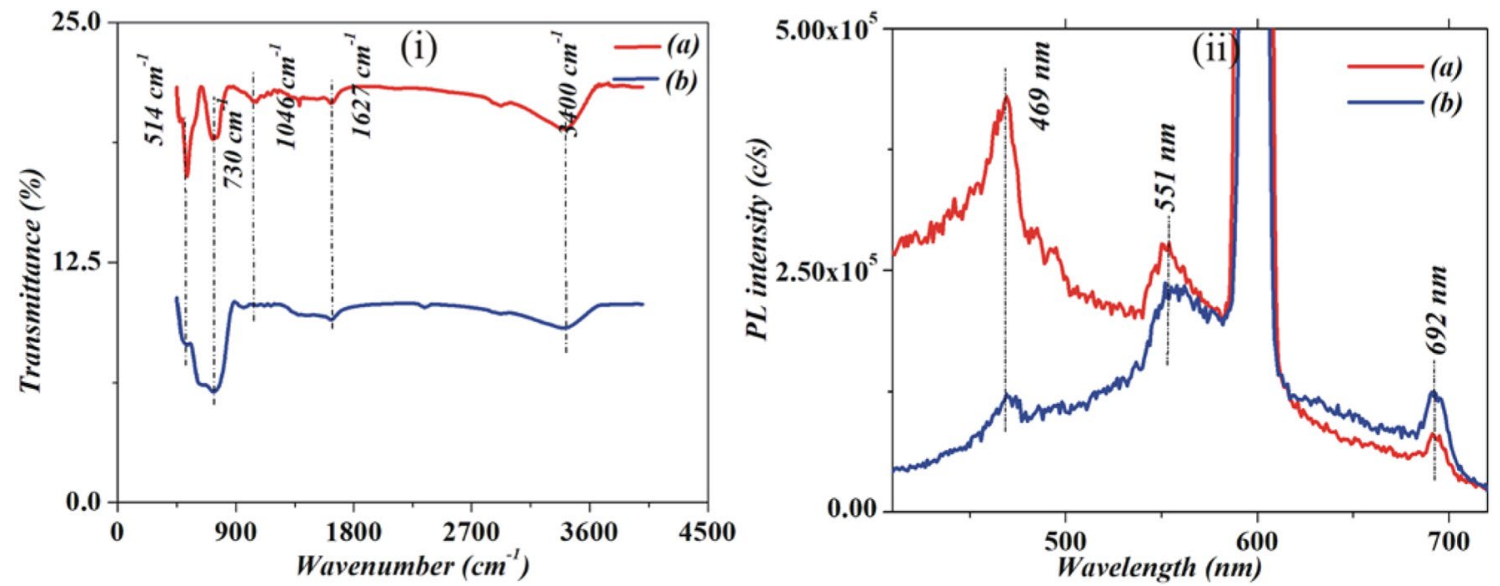

Fig. 4 (i) Infrared spectra of (a) H-MnT and (b) S-MnT; (ii) Emission spectra of (a) H-MnT and (b) S-MnT

the composites. Generally, the octahedral coordinated $\mathrm{Mn}^{2+}$ ions are known to yield an orange to red emission, whereas tetrahedral coordinated ones exhibit a green emission [49-51]. Thus, PL spectra confirm the presence of both octahedral coordinated $\mathrm{Mn}^{2+}$ ions and tetrahedral coordinated $\mathrm{Mn}^{2+}$ ions in the composites.

\subsection{BET analysis results}

The synthesized S-MnT sample (Fig. 5a) indicated type IV isotherm according to IUPAC classification and exhibited $\mathrm{H}-2$ type hysteresis loop corresponding to mesoporous nature [52]. It also indicates the existence of narrow slit shaped pores [52]. At a relative pressure of 0.05 , the first layer on the sample surface gets filled up which is indicated by the first inflection point $A$. The linear region (B) in the isotherm is attributed to the multilayer adsorption on the surface. BET method has been utilized to estimate the surface area using multi-point BET Eq. (4) indicated as follows: [52]
$\frac{1}{W\left[\frac{P_{0}}{P}-1\right]}=\frac{1}{W_{m} C}+\frac{C-1}{W_{m} C}\left(\frac{P}{P_{0}}\right)$

where $W_{m}$ indicates the adsorbate weight covering the surface and $W$ is the gas accumulated at $P / P_{0}$. By plotting $1 /\left[\mathrm{W}\left(\mathrm{P} / \mathrm{P}_{0}\right)-1\right]$ versus $\mathrm{P} / \mathrm{P}_{0}$, we obtained a linear curve (Fig. 5b) within $0.05<P / P_{0}<0.35$ range. This proves that the isotherm data conforms well to the BET model.

The BJH method was then employed to determine the pore size distribution (Fig. 5c).

The surface area value for S-MnT is $18.14 \mathrm{~m}^{2} / \mathrm{g}$. It is well known that mesopores and high surface area are beneficial for the adsorption and diffusion of the reactants [9]. As surface area increases, light harvesting capacity of the photocatalyst increases [53] which cause a significant increase in the interfacial charge transfer rate [54]. Also, the availability of active surface area differs depending on nanostructure dimensions [55]. Peter et al. [56] observed that reduction in dimensionality enhanced the available active surface area. S-MnT also shows a wider PSD which
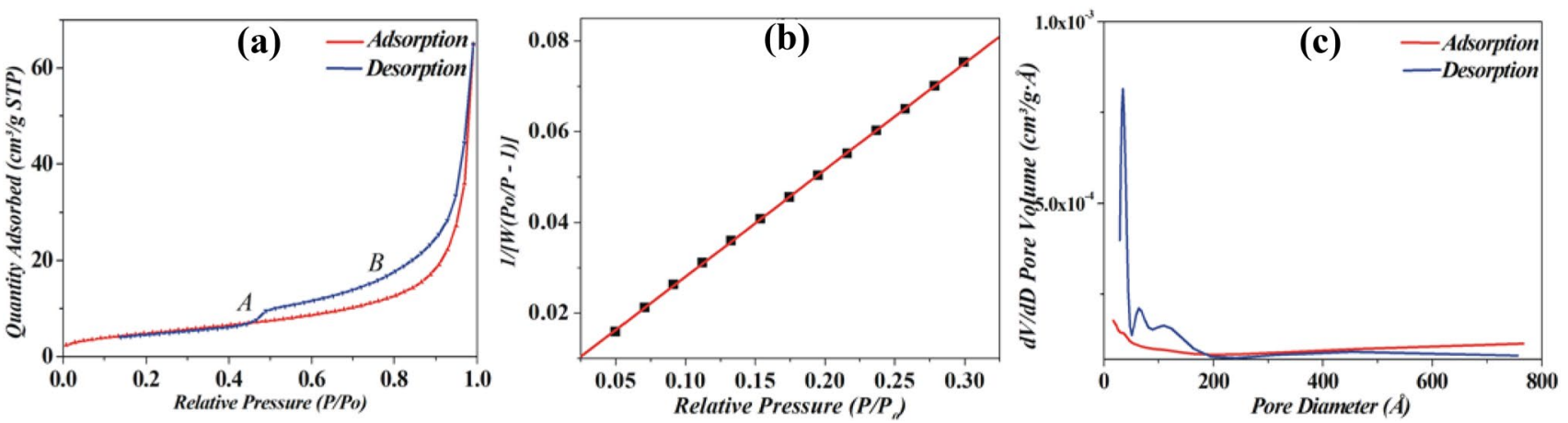

Fig. 5 a Adsorption-desorption isotherm of S-MnT b BET surface area linear plot of S-MnT c Differential mesopore pore size distribution (BJH method) of S-MnT

\section{SN Applied Sciences}


is suitable for energy applications and environmental remediation.

\subsection{Analysis of photocatalytic properties}

Malachite green (MG) is an organic pollutant present in aquatic ecosystems widely used in agriculture as a biocide [57]. The photocatalytic behaviour of the composites was analysed by monitoring their MG decomposition rates under UV radiation at neutral $\mathrm{pH}$. The UV irradiation dose has been calculated as discussed in [2] and listed in Table 1. Dark experiments were carried out for $1 \mathrm{~h}$ and the adsorption ability of the composites was found to be less than $10 \%$ (Fig. 6i). Negative control experiments (without catalyst) were carried out and decomposition was found to be negligible in absence of photocatalyst. The MG solution along with the added photocatalyst was then subjected to UV irradiation and the progress of the reaction was followed by monitoring the intensity of MG absorption bands at $618 \mathrm{~nm}, 315 \mathrm{~nm}$ and $418 \mathrm{~nm}$ respectively. A change in absorbance intensity as function of time was observed (Figure S1). The kinetics of heterogeneous catalytic processes can be best described by Langmuir-Hinshelwood model that takes the sorption effect into consideration. Dye molecules tend to get adsorbed on the active sites of the photocatalyst before the reaction starts [58]. The expression for rate of the reaction (5) that changes with time is given by [59]

$r=-\frac{d A}{d t}=\frac{k_{r} K A}{1+K A}$

where $A$ is the dye concentration at any time $t, A_{o}$ is the initial dye concentration, $\mathrm{k}_{\mathrm{r}}$ is the reaction rate constant and $\mathrm{K}$ is the adsorption coefficient of the dye MG. Rate of photodegradation of organic compounds, in general, follow first order reaction kinetics. For pseudo first order reaction $(K A \ll 1)$

$\frac{d A}{d t}=-k_{r} K A$

$\frac{d A}{d t}=-k_{1} A$

where $k_{1}$ is the pseudo first order reaction rate constant.To make the concentration-time relationship linear

Table 1 Calculated parameters of photocatalytic activity for MnT nanocomposites

\begin{tabular}{llllllcr}
\hline Sample type & Time $(\mathrm{min})$ & $\begin{array}{l}\text { UV radiation } \\
\text { dose }\left(10^{-8}\right) \\
\left(\mathrm{Jsm}^{2}\right)\end{array}$ & $\begin{array}{l}\text { Degradation } \\
\text { efficiency PD (\%) }\end{array}$ & $\begin{array}{l}\text { Pseudo first order rate } \\
\text { constant }\left(\mathrm{k}_{1}\right) \mathrm{min}^{-1}\end{array}$ & $\begin{array}{l}\text { Correlation } \\
\text { coefficient } R^{2}\end{array}$ & $\begin{array}{l}\text { Error } \chi^{2} \\
\text { 1st cycle } \\
\text { (As such) }\end{array}$ & $\begin{array}{l}\text { 5th cycle } \\
\text { (Recycled) }\end{array}$ \\
\hline H-MnT & 60 & 3.451 & 92.14 & .0445 & .0399 & .9747 \\
S-MnT & 60 & 3.451 & 99.61 & .0788 & .0689 & .9576 \\
S-MnT with sonicated $\mathrm{H}_{2} \mathrm{O}_{2}$ & 50 & 2.397 & 99.61 & .0815 & .0883 & .9861 & 18.08 \\
S-MnT with directly added $\mathrm{H}_{2} \mathrm{O}_{2}$ & 30 & 2.397 & 91.31 & .0986 & .0795 & .9670 \\
\hline
\end{tabular}

Up to four significant figures except time
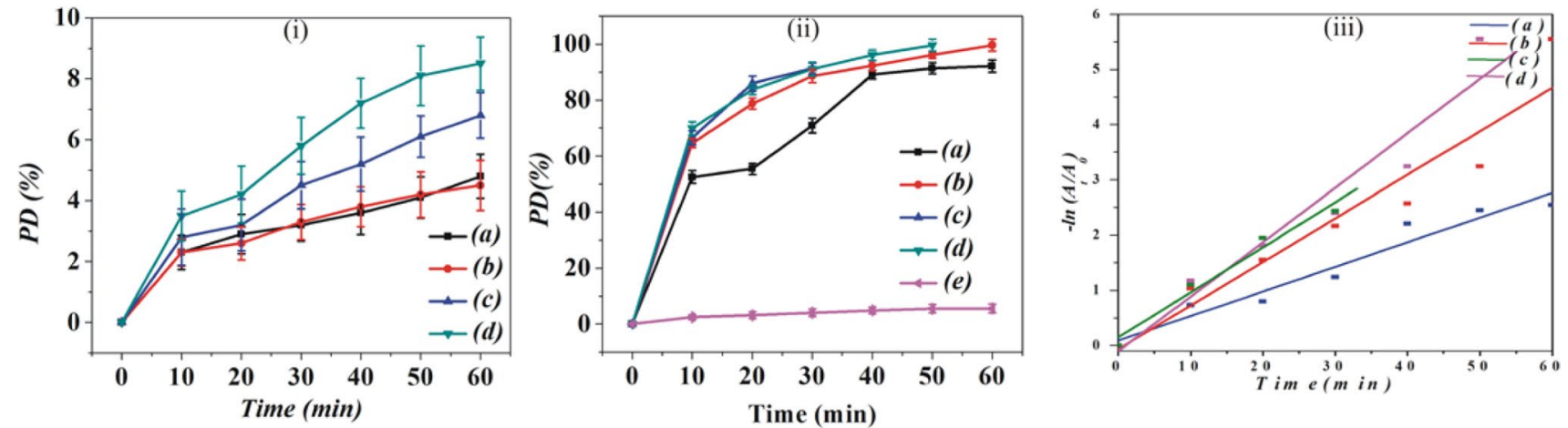

Fig. 6 (i) Dark experiments to investigate adsorption behaviour (ii) Photocatalytic MG contaminant decomposition efficiency and (iii) Reaction rate evaluation plot of (a) H-MnT and (b) S-MnT (c) S-MnT with directly added $\mathrm{H}_{2} \mathrm{O}_{2}$ (d) S-MnT with sonicated $\mathrm{H}_{2} \mathrm{O}_{2}$ and (e) no photocatalyst 
$\ln \left(\frac{A_{t}}{A_{o}}\right)=-k_{1} t$

On plotting $-\ln \left(A_{t} / A_{o}\right)$ as a function of time, the constant $k_{1}$ can be easily determined from the slope of linear best fit. The decolourization efficiency was calculated using [60]

$P D=\frac{\left(A_{0}-A_{t}\right)}{A_{0}} \times 100$

where $A_{o}$ and $A_{t}$ denote dye concentrations before and after photo-irradiation. Figure 6ii shows the time dependent percentage decolourization efficiency (PD) of MG solution $(100 \mathrm{mg} / \mathrm{L})$ under UV irradiation in contact with the composites, and also without the presence of the photocatalyst for MG $618 \mathrm{~nm}$ absorption peak. The PD values corresponding to $315 \mathrm{~nm}$ and $418 \mathrm{~nm}$ peaks of MG have been provided in Table $\mathrm{S} 1$ in Supplementary material. The composites were found to exhibit enhanced photoactivity in comparison to similar reported materials under UV radiation $[61,62]$. It has already been discussed that $\mathrm{H}_{2} \mathrm{O}_{2}$ is a promising electron acceptor that tends to enhance the overall reaction rate [63]. However, addition of $\mathrm{H}_{2} \mathrm{O}_{2}$ in large amounts can have a deteriorating effect on it [64, 65]. Experiments were carried out with different amounts of $\mathrm{H}_{2} \mathrm{O}_{2}(0.5-5 \mathrm{~mL})$ and $2 \mathrm{~mL} \mathrm{H}_{2} \mathrm{O}_{2}$ was found to be the optimal dosage. To underline the sonication effect, this $\mathrm{H}_{2} \mathrm{O}_{2}$ was added in two ways-once directly and once after being sonicated. S-MnT with sonicated $\mathrm{H}_{2} \mathrm{O}_{2}$ showed the best photoactivity which confirmed that sonochemistry has a role in inhibition of electron-hole recombination. Probably, sonochemistry led to the uniform dispersion of $\mathrm{H}_{2} \mathrm{O}_{2}$ in the photocatalyst solution which accelerated the process of radical formation. The estimated values of $\mathrm{k}_{1}$, corresponding correlation coefficients $\left(\mathrm{R}^{2}\right), \mathrm{PD}$ efficiencies and error (chi-square $\chi^{2}$ ) values are listed in Table 1 (for pseudo first order). Figure 6iii provides the values of the pseudo first order rate constant obtained from the linear regression curves.

The stability is essential for its practical application. A cycle experiment of degrading MG in aqueous solutions over the composites was conducted. Results (Table 1) showed that $\mathrm{S}-\mathrm{MnT}$ with sonicated $\mathrm{H}_{2} \mathrm{O}_{2}$ still held high photocatalytic activity after five cycles (Fig. 7).

The mechanism of photocatalysis is described as follows: On irradiating the reaction solution with UV light, photoexcited charge carriers get formed (Eq. (10)).

Photoexcitation : MnT $+h v(U V) \rightarrow M n T\left(e^{-}(C B)+h^{+}(V B)\right)$

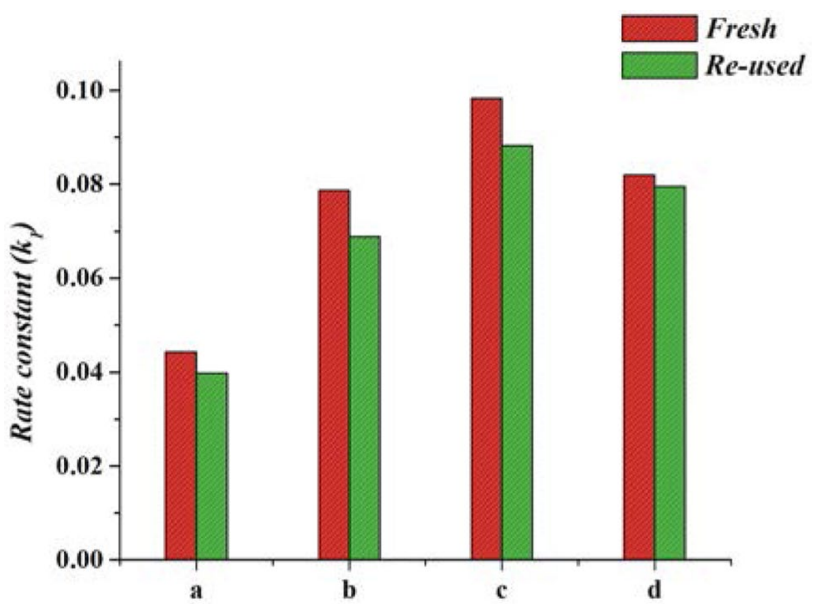

Fig. 7 Rate constant comparison plot for of a H-MnT and b S-MnT c S-MnT with sonicated $\mathrm{H}_{2} \mathrm{O}_{2}$ and d S-MnT with directly added $\mathrm{H}_{2} \mathrm{O}_{2}$

where $h v=$ photons, $h^{+}=$holes, proton $=\mathrm{H}^{+}, \mathrm{CB}$ is conduction band, $\mathrm{VB}$ is valence band and $e^{-}=$electrons.

Magesh et al. [66] calculated the conduction band potential $\left(\mathrm{E}_{\mathrm{CB}}\right)$ for $\mathrm{TiO}_{2}\left(\mathrm{E}_{\mathrm{g}}=3.2 \mathrm{eV}\right)$ in reference to normal hydrogen electrode (NHE) as $-0.29 \mathrm{eV}$ while $\mathrm{Li}$ et al. [67] found that $\mathrm{E}_{\mathrm{CB}}$ for $\mathrm{Mn}_{2} \mathrm{O}_{3}\left(\mathrm{E}_{\mathrm{g}}=3.2 \mathrm{eV}\right)$ is $-1 \mathrm{eV}$. Clearly, $\mathrm{E}_{\mathrm{CB}}$ for $\mathrm{Mn}_{2} \mathrm{O}_{3}$ is more negative than that of $\mathrm{TiO}_{2}$. So, it is expected that at the junction of the $\mathrm{MnT}$ composite, there will be a transfer of excited electrons from $\mathrm{Mn}_{2} \mathrm{O}_{3}$ to the conduction band of $\mathrm{TiO}_{2}$.

The holes in the valence band will give rise to $\mathrm{OH}$ radicals by the oxidation of water as given by Eqs. (11) and (12).

$\mathrm{MnT}\left(h^{+}(V B)\right)+$ water $\rightarrow \mathrm{MnT}+$ proton $+\cdot \mathrm{OH}$

$\mathrm{MnT}\left(h^{+}(\mathrm{VB})\right)+\mathrm{OH}^{-} \rightarrow \mathrm{MnT}+\cdot \mathrm{OH}$

Some excited electrons may get transferred to adsorbed oxygen molecules reducing molecular oxygen to superoxide radicals $\left(\mathrm{O}_{2}^{-}\right)[23,68-71]$.

Oxygenionosorption : $\operatorname{MnT}\left(e^{-}(C B)\right)+\mathrm{O}_{2} \rightarrow \mathrm{MnT}+\mathrm{O}_{2}^{-}$.

Also, as $\mathrm{E}_{\mathrm{CB}}$ for $\mathrm{TiO}_{2}$ is more negative than that for $\mathrm{O}_{2} /$ $\mathrm{H}_{2} \mathrm{O}_{2}\left(0.682 \mathrm{eV}\right.$ vs NHE), $\mathrm{H}_{2} \mathrm{O}_{2}$ may be produced in the process [72].

$\mathrm{O}_{2}^{-\cdot} \stackrel{\text { reduction }}{\longrightarrow} \mathrm{H}_{2} \mathrm{O}_{2}$

In case of added $\mathrm{H}_{2} \mathrm{O}_{2}$, Ti-peroxo species tend to be formed at the solution interface [73-76]. Ohno et al. [75] through FTIR and X-ray photoelectron spectroscopy (XPS) and Lousada et al. [77] through density functional theory studies have confirmed the formation of such peroxo 
Table 2 Comparison of photocatalytic abilities of some composites for MG degradation

\begin{tabular}{|c|c|c|c|c|c|c|}
\hline Photocatalyst & Dye conc (mg/L) & Catalyst dose $(\mathrm{g} / \mathrm{L})$ & PD (\%) & Time (min) & Light source & References \\
\hline $\mathrm{TiO}_{2}$ rutile & 100.0 & 0.050 & 97.00 & 180 & UV & {$[2]$} \\
\hline Commercial $\mathrm{TiO}_{2}$ & 100.0 & 0.050 & 96.00 & 210 & UV & {$[2]$} \\
\hline $\mathrm{TiO}_{2}$-DAS & - & 0.005 & 60.40 & 120 & UV & [3] \\
\hline $\mathrm{TiO}_{2}-\mathrm{DAS}-\mathrm{SiO}_{2}$ & - & 0.005 & 21.60 & 120 & UV & [3] \\
\hline $\mathrm{MnS}$ & - & 0.005 & - & 80 & UV & {$[81]$} \\
\hline MnS & - & 0.050 & 56.60 & 300 & UV & {$[82]$} \\
\hline MnS-DAS & - & 0.050 & 82.80 & 300 & UV & {$[82]$} \\
\hline- & 12.50 & - & 70.00 & 120 & Ultrasound (135 W) & [83] \\
\hline $\mathrm{TiO}_{2}$ & 10.00 & $0.100-0.500$ & 100.0 & $30-60$ & UV + Ultrasound & [83] \\
\hline A. Flavus & 0.030 & - & 99.70 & 8640 & - & {$[84]$} \\
\hline A. Solani & 0.030 & - & 91.70 & 8640 & - & [84] \\
\hline ZnS:Mn & 2.000 & - & 91.00 & 60 & Visible & {$[85]$} \\
\hline $\mathrm{ZnS}: \mathrm{Mn} / \mathrm{ZnS}$ & 2.000 & - & 98 & 60 & Visible & {$[85]$} \\
\hline $\mathrm{Au} / \mathrm{NaNbO}_{3}$ & 100.0 & $0.8-1.6$ & $87.00-94.00$ & 60 & Visible & {$[86]$} \\
\hline Ca doped ceria & 6.000 & 0.100 & 93.00 & 90 & UV & [87] \\
\hline $\begin{array}{l}\mathrm{ZnO} \text { capped with ethylene } \\
\text { diamine tetra acetic acid }\end{array}$ & 9.270 & 0.002 & 94.10 & 41 & Simulated sunlight & {$[88]$} \\
\hline ZnO capped with citric acid & 9.270 & 0.002 & 80.10 & 61 & Simulated sunlight & {$[88]$} \\
\hline ZnO capped with oleic acid & 9.270 & 0.002 & 67.60 & 61 & Simulated sunlight & {$[88]$} \\
\hline Nickel vanadate & 927.0 & 0.100 & - & 100 & Visible & [89] \\
\hline $\mathrm{TiO}_{2}$ & 50.00 & 0.500 & 99.90 & 240 & UV & {$[90]$} \\
\hline $\mathrm{CoTiO}_{3}$ & - & - & 96.30 & 180 & UV & [3] \\
\hline $\mathrm{CO}_{2} \mathrm{TiO}_{4}$ & - & - & 88.00 & 200 & UV & [3] \\
\hline $\mathrm{ZnO}$ nanorods on $\mathrm{RGO} / \mathrm{Ni}$ foam & 20.00 & - & 100.0 & 15 & UV & [91] \\
\hline ZnO/Ni foam & 20.00 & - & 68.00 & 15 & UV & [91] \\
\hline RGO/Ni foam & 20.00 & - & 38.00 & 15 & UV & [91] \\
\hline $\mathrm{H}-\mathrm{MnT}$ & 927.0 & 0.050 & 92.10 & 60 & UV & Present work \\
\hline S-MnT & 927.0 & 0.050 & 99.60 & 60 & UV & Present work \\
\hline S-MnT with direct $\mathrm{H}_{2} \mathrm{O}_{2}$ & 927.0 & 0.050 & 91.30 & 30 & UV & Present work \\
\hline S-MnT with sonicated $\mathrm{H}_{2} \mathrm{O}_{2}$ & 927.0 & 0.050 & 99.60 & 50 & UV & Present work \\
\hline
\end{tabular}

Up to 4 significant figures except time

species. These reactive oxygen species $\left(\mathrm{OH}, \mathrm{O}_{2}^{-} ; \mathrm{H}_{2} \mathrm{O}_{2}\right.$ and peroxo species) ultimately lead to transformation of the chromophoric groups in the dye. MG is a dye containing nitrogen. Depending on the oxidation state of the nitrogen atom, $\mathrm{MG}$ may release $\mathrm{NH}_{4}{ }^{+}, \mathrm{NO}_{3}{ }^{-}$or even $\mathrm{N}_{2}$ [78]. However, the complete mineralization of the dye requires highly energetic free radicals which are preferentially generated under UV irradiation. In this context, Bae et al. [79] has documented that the TOC removal efficiencies of titania based catalysts are much higher under UV irradiation.

Also, the defect content in the composites could be responsible for the efficient photoactivity shown by them. In this regard, Zheng et al. [80] have explained that defects like interstitial oxygen generate shallow levels near the valence band while defects like oxygen vacancies act as electron acceptors. Thus, interfacial charge transfer prolongs the lifetime of the carriers by suppressing the recombination of electron-hole pairs. However, in the future, such parameters need to be studied on a theoretical platform.

A comparison of photocatalytic ability of synthesized $\mathrm{MnT}$ composites with other reported composites in degrading MG is illustrated in Table 2.

\section{Conclusions}

The present study outlined a reliable, cost-effective sonochemical method to synthesize binary nanocomposites of manganese and titanium oxides that can be extended for the preparation of other binary metal oxide composites. The composites were used to test the photocatalytic degradation of MG in the aqueous solution. The decolourization rate of S-MnT photocatalyst with ultrasound 
functionalized $\mathrm{H}_{2} \mathrm{O}_{2}$ was found to be higher than that of $\mathrm{H}-\mathrm{MnT}$, bare S-MnT and S-MnT with directly added $\mathrm{H}_{2} \mathrm{O}_{2}$. It could be proposed that unique nanorod-nanodisk morphology, defect concentration and sonochemistry played a vital role in reducing the chances of electron hole recombination thereby enhancing pollutant degradation rate. Luminescence studies also predict possible optoelectronic applications for transition metal oxide nanomaterials. The composites exhibited good stability predicting potential applications in waste water treatment, environment protection and even in energy preservation.

Acknowledgements Authors highly appreciate the DST-PURSE program of Kalyani University and the DST-FIST Project (SR/FST/PSI175/2012). The authors are indebted to Dr Sayan Bhattacharyya, IISER Kolkata for surface area measurements. Sincere acknowledgement is due for the assistance under DST-FIST and UGC-SAP programs to the Dept. of Chemistry, Kalyani University. Gopala Krishna Darbha is thankful to the support from SERB, Ramanujan Fellowship Grant (SB/ S2/RJN-006/2016) and SERB-ECR project (ECR/2017/000707), India.

\section{Compliance with ethical standards}

Conflict of interest The authors declare that they have no conflict of interest.

\section{References}

1. Soler-Illia GJAA, Sancchez C, Lebeau B, Patarin J (2002) Chemical strategies to design textured materials: from microporous and mesoporous oxides to nanonetworks and hierarchical structures. Chem Rev 102:4093-4138

2. Purkayastha MD, Middya S, Datta J, Ray PP, Biswas BD, Sarkar M, Darbha GK, Singh N, Majumder TP, Saha P, Das D (2019) The carrier transport properties and photodegradation ability of low temperature synthesized phase pure rutile titanium oxide nanostructured materials Mat. Chem Phys 226:362-370

3. Purkayastha MD, Sarkar M, Majumder TP (2019) Enhanced UV shielding properties of DAS based nanocomposites. Optik (Stuttg) 182:469-478

4. Purkayastha MD, Ray PP, Majumder TP, Sarkar M (2019) Spectroscopic characterization and photocatalytic degradation ability of ternary oxides of cobalt. Int J Innov Res Phys Accept Artic

5. Purkayastha MD, Singh N, Darbha GK, Majumder TP (2020) Strain influence on the structural properties of nitrogen and fluorine codoped $\mathrm{TiO}_{2}$. Optik (Stuttg) 206:164029

6. Harir M, Gaspar A, Kanawati B, Fekete A, Frommberger M, Martens D, Kettrup A, El Azzouzi M, Schmitt Kopplin P (2008) Photocatalytic reactions of imazamox at $\mathrm{TiO}_{2}, \mathrm{H}_{2} \mathrm{O}_{2}$ and $\mathrm{TiO}_{2} / \mathrm{H}_{2} \mathrm{O}_{2}$ in water interfaces: kinetic and photoproducts study. Appl Catal B Environ 84:524-532

7. Sivakumar S, Selvaraj A, Ramasam AK, Balasubramanian V (2013) Enhanced photocatalytic degradation of reactive dyes over $\mathrm{FeTiO}_{3} / \mathrm{TiO}_{2}$ heterojunction in the presence of $\mathrm{H}_{2} \mathrm{O}_{2}$. Water Air Soil Pollut 224:1529-1542

8. Song ZQ, Wang SB, Yang W, Mo L, Wang H, Yan H (2004) Synthesis of manganese titanate $\mathrm{MnTiO}_{3}$ powders by a sol-gel hydrothermal method. Mater Sci Eng, B 113:121-124

9. Xue $M$, Huang L, Wang JQ, Wang Y, Gao L, Zhu JH, Zou ZG (2008) The direct synthesis of mesoporous structured $\mathrm{MnO}_{2} /$
$\mathrm{TiO}_{2}$ nanocomposite: a novel visible light active photocatalyst with large pore size. Nanotechnology 19:185604

10. $\mathrm{Li} \mathrm{J}$, Zeng HC (2006) Preparation of monodisperse $\mathrm{Au} / \mathrm{TiO}_{2}$ nanocatalysts via self- assembly. Chem Mater 18:4270-4277

11. Kharkwal M, Uma S, Nagarajan R (2010) Use of a chelating agent for the synthesis of high surface area pyrophanite $\mathrm{MnTiO}_{3}$ powders Mater. Lett. 64:692-694

12. Sinha AK, Suzuki K (2005) Preparation and characterization of novel mesoporous ceria-titania. J Phys Chem B 109:1708-1714

13. Ghows N, Entezari MH (2010) Ultrasound with low intensity assisted the synthesis of nanocrystalline $\mathrm{TiO}_{2}$ without calcination. Ultrason Sonochem 17:878-883

14. Guo J, Zhu S, Chen Z, Li Y, Yu Z, Liu Q, Li J, Feng C, Zhang $\mathrm{D}$ (2011) Sonochemical synthesis of $\mathrm{TiO}_{2}$ nanoparticles on graphene for use as photocatalyst Ultrason. Sonochem 18:1082-1090

15. Arenas $M C$, Rodiguez-Nunez LF, Rangel $D$, Martinez-Alvarez O, Martinez-Alonso C, Castano VM (2013) Simple one step ultrasonic synthesis of anatase titania/polypyrrole nanocomposites Ultrason. Sonochem 20:777-784

16. Vinoth R, Karthik P, Devan K, Neppolian B, Muthupandian AK (2017) $\mathrm{TiO}_{2}-\mathrm{NiO} p-n$ junction nanocomposite with enhanced sonophotocatalytic activity under diffused sunlight Ultrason. Sonochem 35:655-663

17. Tryba B, Toyoda M, Morawski AW, Nonaka R, Inagaki M (2007) Photocatalytic activity and $\mathrm{OH}$ radical formation on $\mathrm{TiO}_{2}$ in the relation to crystallinity. Appl Catal B 71:163-168

18. Tachikawa T, Majima T (2010) Single molecule, single particle fluorescence imaging of $\mathrm{TiO}_{2}$ based photocatalytic reactions. Chem Soc Rev 39:4802-4819

19. Fujihira M, Satoh Y, Osa T (1981) Heterogeneous photocatalytic oxidation of aromatic compounds on titanium dioxide. Nature 298:206-208

20. Kim W, Tachikawa T, Moon G, Majima T, Choi W (2014) Molecular-level understanding of the photocatalytic activity difference between anatase and rutile nanoparticles. Angew Chem Int Ed 53:14036-14041

21. Hirakawa T, Yawata K, Nosaka Y (2007) Photocatalytic reactivity for $\mathrm{O}_{2}^{-}$and $\mathrm{OH}$ radical formation in anatase and rutile $\mathrm{TiO}_{2}$ suspension as the effect of $\mathrm{H}_{2} \mathrm{O}_{2}$ addition. Appl Catal $\mathrm{A}$ 325:105-111

22. Zhang J, Nosaka $Y$ (2014) Mechanism of the $\mathrm{OH}$ radical generation in photocatalysis with $\mathrm{TiO}_{2}$ of different crystalline types. J Phys Chem C 118:10824-10832

23. Kakuma Y, Nosaka A, Nosaka Y (2015) Difference in $\mathrm{TiO}_{2}$ photocatalytic mechanism between rutile and anatase studied by the detection of active oxygen and surface species in water. Phys Chem Chem Phys 17:18691-18698

24. Nosaka Y, Nosaka A (2016) Chapter 7: Kinetic processes in the presence of photogenerated charge carriers. In: Schneider J, Bahnemann D et al (eds) Photocatalysis: fundamentals and perspectives. Royal Society of Chemistry, London, pp 165-184

25. Hu XL, Zhu YJ, Wang SW (2004) Sonochemical and microwave assisted synthesis of linked single crystalline $\mathrm{ZnO}$ rods. Mater Chem Phys 88:421-426

26. Prasad K, Pinjari DV, Pandit AB, Mhaske ST (2010) Phase transformation of nanostructured titanium dioxide from anatase to rutile via combined ultrasound assisted sol-gel method. Ultrason Sonochem 17:409-415

27. Ling J, Wang K, Wang Z, Huang $H$, Zhang G (2019) Enhanced piezoelectric-induced catalysis of $\mathrm{SrTiO}_{3}$ nanocrystal with welldefined facets under ultrasonic vibration. Ultrason Sonochem. https://doi.org/10.1016/j.ultsonch.2019.104819

28. Kockmann A, Hesselbach J, Zellmer S, Kwade A, Garnweitner G (2015) Facile surface tailoring of metal oxide nanoparticles via a two-step modification approach. RSC Adv 5:60993-60999 
29. Enhessari M, Parviz A, Karamali E, Ozaee K (2012) Synthesis, characterisation and optical properties of $\mathrm{MnTiO}_{3}$ nanopowders. J Exp Nanosci 7:327-335

30. Kolodziejczak-Radzimska A, Jesionowski J (2014) Zinc oxidefrom synthesis to application: a review. Materials (Basel) 7:2833-2881

31. Elser MJ, Berger T, Brandhunber D, Bernardi J, Diwald Knozinger E (2006) Particles coming together: electron centres in adjoined $\mathrm{TiO}_{2}$ nanocrystals. J Phys Chem 110:7605-7608

32. Monatzer M, Behzadnia A, Pakdel E, Rahimi MK, Moghadam MB (2011) Photoinduced silver on nano titanium dioxide as an enhanced antimicrobial agent for wool. J Photochem Photobiol, B 103:207-214

33. Patterson AL (1939) The Scherrer formula for x-ray particle size determination. Phys Rev 56:978-982

34. Das SK, Rou BK (2015) Magnetic and ferroelectric properties of $\mathrm{Zn}$ and $\mathrm{Mn}$ co-doped $\mathrm{BaTiO}_{3}$. Chin Phys B 24:067702

35. Smith AM, Nie $S$ (2010) Semiconductor nanocrystals: structure, properties, and band gap engineering. Acc Chem Res 43:190-200

36. Zhang $\mathrm{H}$, Zhu H, Sun $\mathrm{R}$ (2012) Fabrication of photocatalytic $\mathrm{TiO}_{2}$ nanoparticle film on PET fabric by hydrothermal method. Text Res J 82:747-754

37. Linsebigler AL, Lu G, Yates JT (1995) Photocatalysis on $\mathrm{TiO}_{2}$ surfaces: principles, mechanisms and selected results. Chem Rev 95:735-758

38. Binas V, Venieri D, Kotzias D, Kiriakidis G (2017) Modified $\mathrm{TiO}_{2}$ based photocatalysts for improved air and health quality. $J$ Materiomics 3:3-16

39. Sharrouf $M$, Awad R, Roumie M, Marhaba S (2015) Structural, optical and room temperature magnetic study of $\mathrm{Mn}_{2} \mathrm{O}_{3}$ nanoparticles. Mater Sci Appl 6:850-859

40. Sharma YK, Kharkwal MK, Uma S, Nagarajan R (2009) Synthesis and characterisation of titanates of the formula MnTiO3 $(\mathrm{M}=\mathrm{Mn}$, $\mathrm{Fe} \mathrm{Co}, \mathrm{Ni}, \mathrm{Cd}$ ) by co-precipitation of mixed metal oxalates. Polyhedron 28:579-585

41. Gupta SK, Kadam RM, Gupta R, Sahu M, Natarajan V (2014) Evidence for stabilisation of manganese ion as $\mathrm{Mn}$ (II) and $\mathrm{Mn}$ (IV) in $a-\mathrm{Zn}_{2} \mathrm{P}_{2} \mathrm{O}_{7}$ : Probed by EPR, luminescence and electrochemical studies. Mater Chem Phys 145:162-167

42. Tanabe Y, Sugano $S$ (1954) On the absorption spectra of complex ions. J Phys Soc 9:753-766

43. Ye T, Dong Z, Zhao Y, Yu J, Wang F, Guo S, Zuo Y (2011) Controllable fabrication of perovskite $\mathrm{SrZrO}_{3}$ hollow cuboidal nanoshells Cryst. Eng Commun 13:3842-3847

44. Pathak N, Gupta SK, Ghosh PS, Arya A, Natarajan V, Kadam RM (2015) Probing local site environments and distribution of manganese in $\mathrm{SrZrO}_{3}$ : $\mathrm{PL}$ and EPR spectroscopy complimented by DFT calculations. RSC Adv 5:17501-17513

45. Raul SZ, Marcelino BF, Umapada P (2011) Photoluminescence and Raman scattering in Ag-doped $\mathrm{ZnO}$ nanoparticles. J Appl Phys 109:014308

46. Souza AE, Santos GTA, Barra BC, Macedo WD Jr, Teixeira SR, Santos CM, Senos AMOR, Amaral L, Longo E (2012) Photoluminescence of $\mathrm{SrTiO}_{3}$ : influence of particle size and morphology. Cryst Growth Des 12:5671-5679

47. da Silva LF, Avansi W, Moreira ML, Mesquita A, Maia LJQ, Andrés J, Longo E, Mastelaro VR (2012) Relationship between crystal shape, photoluminescence and local structure in $\mathrm{SrTiO}_{3}$ synthesized by microwave assisted hydrothermal method. J Nanomater 2012:890397

48. Wang $\mathrm{B}$, Lin $\mathrm{H}$, Xu J, Chen $\mathrm{H}$, Wang YS (2014) $\mathrm{CaMg}_{2} \mathrm{Al}_{16} \mathrm{O}_{27}$ : $\mathrm{Mn}^{4+}$ based red phosphor: a potential color converter for high-powered warm w-led. ACS Appl Mater Interfaces 6:22905-22913

49. Shang $M$, Geng D, Zhang Y, Li G, Yang D, Kang X, Lin J (2012) Luminescence and energy transfer properties of
$\mathrm{Ca}_{8} \mathrm{Gd}_{2}\left(\mathrm{PO}_{4}\right) 6 \mathrm{O}_{2}: \mathrm{A}\left(\mathrm{A}=\mathrm{Ce}^{3+} / \mathrm{Eu}^{2+} / \mathrm{Tb}^{3+} / \mathrm{Dy}^{3+} / \mathrm{Mn}^{2+}\right)$ phosphors. J Mater Chem 22:19094-19104

50. Geng D, Li G, Sheng M, Yang D, Zhang Y, Cheng Z, Lin J (2012) Colour tuning via energy transfer in $\mathrm{Sr}_{3} \ln \left(\mathrm{PO}_{4}\right)_{3}: \mathrm{Ce}^{3+} / \mathrm{Tb}^{3+} /$ $\mathrm{Mn}^{2+}$. J Mater Chem 22:14262-14271

51. Liu YF, Zhang X, Hao ZD, Wang XJ, Zhang JH (2011) Tunable full colour emitting $\mathrm{Ca}_{3} \mathrm{Sc}_{2} \mathrm{Si}_{3} \mathrm{O}_{12}: \mathrm{Ce}^{3+}, \mathrm{Mn}^{2+}$ phosphor via charge compensation and energy transfer. Chem Commun 47:10677-10679

52. Do DD (1998) Adsorption analysis: equilibrium and kinetics. Imperial College Press, London

53. Ahmed F et al (2014) Quantum-confinement induced enhancement in photocatalytic properties of iron oxide nanoparticles prepared by lonic liquid. Ceram Int 40:15743-15751

54. Wei Z, Kowalska E, Verrett J, Colbeau-Justin C, Remita H, Ohtani B (2015) Morphology-dependent photocatalytic activity of octahedral anatase particles prepared by ultrasonication hydrothermal reaction of titanates. Nanoscale 7:12392-12404

55. Flores NM, Pal U, Galeazzi R, Sandoval A (2014) Effect of morphology, surface area and defect content on the photocatalytic dye degradation performance of $\mathrm{ZnO}$ nanostructures. RSC Adv 4:41099-41110

56. Peter IJ, Praveen E, Vignesh G, Nithiananthi P (2017) Zinc nanostructures with different morphology for enhanced photocatalytic activity. Mater Res Express 4:124003

57. Raval NP, Shah PU, Shah NK (2017) Malachite green'a cationic dye' and its removal from aqueous solution by adsorption. Appl Water Sci 7:3407-3445

58. Delagado P, Sans MT, Beltvan S (2007) Kinetic study for esterification of lactic acid with ethanol and hydrolysis of ethyl acetate using an ion exchange resin. Chem Eng J 120:111-118

59. Herrmann JM (2010) Photocatalysis fundamentals revisited to avoid mis-conceptions. Appl Catal B Environ 99:461-468

60. Menzinger M, Wolfgang $R$ (1969) The meaning and use of the Arrhenius activation energy. Angew Chem 6:438-444

61. Tateoka A, Sekine Y, Tsuda T, Ohashi T (2005) Manganese oxide photodeposited onto titanium dioxide as a new environmental catalyst. Mater Sci Forum 480/481 117:117-122

62. Subrahmanyam C, Magureanu M, Laub D, Renken A, KiwiMinsker L (2007) Nonthermal plasma abatement of trichloroethylene enhanced by photocatalysis. J Phys Chem C 111:4315-4318

63. Wong CC, Chu W (2003) The hydrogen peroxide assisted photocatalytic degradation of alachlor in $\mathrm{TiO}_{2}$ suspensions. Environ Sci Technol 37:2310-2316

64. Ye H, Lu S (2013) Effect of hydrogen peroxide on the structure and photocatalytic activity of titania. Res Chem Intermed 41:139-149

65. Zang Y, Farnood R (2006) Effect of hydrogen peroxide on the photocatalytic degradation of tert-butyl ether. Top Catal 37:91-96

66. Magesh G, Viswanathan B, Viswanath RP, Varadarajan TK (2009) Photocatalytic behaviour of $\mathrm{CeO}_{2}-\mathrm{TiO}_{2}$ system for the degradation of methylene blue. Indian J Chem 48A:480-488

67. Li F, Wangyang P, Zada A, Humayun M, Wang B, Qu Y (2016) Synthesis of hierarchical $\mathrm{Mn}_{2} \mathrm{O}_{3}$ microspheres for photocatalytic hydrogen production Mater. Res Bull 84:99-104

68. Sahel K, Elsellami L, Mirali I, Dappozze F, Bouhent M, Guillard C (2016) Hydrogen peroxide and photocatalysis. Appl Catal B 188:106-112

69. Jiang T, Wang K, Guo T, Wu X, Zhang G (2020) Fabrication of Z-scheme $\mathrm{MoO}_{3} / \mathrm{Bi}_{2} \mathrm{O}_{4}$ heterojunction photocatalyst with enhanced photocatalytic performance under visible light irradiation. Chin J Catal 41:161-169

70. Sun X, Zhang J, Fu Z (2018) Polyoxometalate cluster sensitized with copper-viologen framework for efficient degradation of 
organic dye in ultraviolet, visible and near-infrared light. ACS Appl Mater Interfaces 10:35671-35675

71. Wang Z, Wang K, Li Y, Jiang L, Zhang G (2019) Novel BiSbO $/$ $\mathrm{BiOBr}$ nanoarchitecture with enhanced visible light driven photocatalytic performance: oxygen-induced pathway of activation and mechanism unveiling. Appl Surf Sci 498:143850

72. Mousavi M, Yangjeh AH, Abitorabi M (2016) Fabrication of novel magnetically separable nanocomposites using graphitic carbon nitride, silver phosphate and silver chloride and their applications in photocatalytic removal of different pollutants using visible light irradiation. J Colloid Interface Sci 480:218-231

73. Regazzoni AE, Mandelbaum P, Matsuyoshi M, Schiller S, Bilmes SA, Blesa MA (1998) Adsorption and photooxidation of salicylic acid on titanium dioxide: a surface complexation description. Langmuir 14:868-874

74. Li X, Chen C, Zhao J (2001) Mechanism of decomposition of $\mathrm{H}_{2} \mathrm{O}_{2}$ on $\mathrm{TiO}_{2}$ surfaces using visible light irradiation. Langmuir 17:4118-4122

75. Ohno T, Masaki Y, Hirayama S, Matsumura M (2001) $\mathrm{TiO}_{2}$ photocatalyzed epoxidation of 1-decene by $\mathrm{H}_{2} \mathrm{O}_{2}$ under visible light. J Catal 204:163-168

76. Pavel CC, Park S, Dreier A, Tesche B, Schmidt W (2006) Structural defects induced in ETS- 10 by postsynthesis treatment with $\mathrm{H}_{2} \mathrm{O}_{2}$ solution. Chem Mater 18:3813-3820

77. Lousada CM, Johansson AJ, Brinck T, Jonsson M (2012) Mechanism of $\mathrm{H}_{2} \mathrm{O}_{2}$ decomposition on transition metal oxide surfaces. J Phys Chem C 116:9533-9543

78. Tanaka K, Padermpole K, Hisanaga T (2000) Photocatalytic degradation of commercial azo dyes. Water Res 34:327-333

79. Bae S, Kim S, Lee S, Choi W (2014) Dye decolourization test for the activity assessment of visible light photocatalysts: realities and limitations. Catal Today 224:21-28

80. Zheng YH, Chen CQ, Zhan YY, Lin XY, Zheng Q, Wei KM, Zhu JF, Zhu YJ (2007) Luminescence and photocatalytic activity of ZnO nanocrystals: correlation between structure and property. Inorg Chem 46:6675-6682

81. Hussain W, Malik H, Hussain RA, Hussain $H$, Greens IR, Marwat $S$, Bahadur A, Iqbal S, Farooq MU, Li H, Badshah A (2019) Synthesis of $\mathrm{MnS}$ from single and multi-source precursors for photocatalytic and battery applications. J Electron Mater 48:2278-2288
82. Biswas BD, Purkayastha MD, Majumder TP (2020) Effect of DAS on the optical and photocatalytic properties of metastable $\gamma$-MnS nanoparticles. Surf Interfaces 19:100469

83. Berberidou C, Poulios I, Xekoukoulotakis NP, Mantzavinos D (2007) Sonolytic, photocatalytic and sonophotocatalytic degradation of malachite green in aqueous solutions. Appl Catal B Environ 74:63-72

84. Ali H, Ahmad W, Haq T (2009) Decolourization and degradation of malachite green by Aspergillus flavus and Alternaria solani. Afr J Biotechnol 8:1574-1576

85. Khaparde AR, Acharya AS (2018) Efficient photocatalytic degradation of malachite green dye under visible irradiation by water soluble ZnS:Mn/ZnS core/shell nanoparticles. AIP Conf Proc 1953:030139

86. Baeissa ES (2016) Photocatalytic degradation of malachite green dye using $\mathrm{Au} / \mathrm{NaNbO}_{3}$ nanoparticles. J Alloys Compd 672:564-570

87. Amar IA, Harara HM, Baqul QA, Qadir MAA, Altohami FA, Ahwidi MM, Abdalsamed IA, Saleh FA (2020) Photocatalytic degradation of malachite green dye under UV light irradiation using calciumdoped ceria nanoparticles. Asian J Nanosci Mater 3:1-14

88. Meena S, Vaya D, Das BK (2016) Photocatalytic degradation of malachite green dye by modified $\mathrm{ZnO}$ nanomaterial. Bull Mater Sci 39:1735-1743

89. Rathore R, Ameta R, Ameta SC (2014) Photocatalytic degradation of malachite green over nickel vanadate powder. Acta Chim Pharm Indica 4:213-220

90. Chen CC, Lua CS, Chung YC, Jan JL (2007) UV light induced photodegradation of malachite green on $\mathrm{TiO}_{2}$ nanoparticles. J Hazard Mater 141:520-528

91. Wang Q, Zhang C, Zhou L, Zhang D, Tong Z, Liu Y, Chen J (2018) Efficient photocatalytic degradation of malachite green in sea water by the hybrid of $\mathrm{ZnO}$ nanorods grown on 3D reduced graphene oxide (RGO)/Ni foam. Materials (Basel) 11:1004

Publisher's Note Springer Nature remains neutral with regard to jurisdictional claims in published maps and institutional affiliations. 